\title{
The Integration of Technology and Culture of Sportswear Products under the Trend of Start-ups and Innovation Bo Pang ${ }^{1}$
}

${ }^{1}$ College of Humanities \& Sciences of Northeast Normal University, Changchun City, Jilin Province, China, 130000

Keywords: Start-ups and innovation trend; Sportswear; Science and technology; Cultural; Integration

\begin{abstract}
Mass entrepreneurship and innovation" is an important development strategy put forward by our country. "Double hit" era is not only to promote China's economic development of a good medicine, but also push the important changes of value orientation and cognitive development. To achieve product technology and cultural integration of China's sports apparel product development direction, the development of the entire sports apparel industry has important significance. This paper starts from the characteristics of the era of start-ups and innovation, expounds the present situation and the exposed problems of sportswear industry in our country, and points out the necessity of realizing the integration of science and technology and culture of sportswear products, and explores the characteristics of sports apparel products in cultural integration of the specific implementation of the strategy and pointed out the direction for the development of China's sportswear industry.
\end{abstract}

\section{Introduction}

With the advent of the era of start-ups and innovation, "mass entrepreneurship and innovation" has not only a show of economic phenomena, but also a kind of ideological emancipation, a value orientation of change and development. The development of the national economy and social progress, people's living standards have been an unprecedented upgrade. The pursuit of health, fashion life has become the most important thing for people. The gradual formation and promotion of social health awareness has promoted the development of China's sportswear market, and its consumption level has been improved year by year. Benefit from such a development situation, China's sportswear industry has been getting rapid development, a lot of Chinese people in recent years are rapid occupying the domestic consumer market, with foreign veteran sports brand also share a share. But the advent of the era of start-ups and innovation, the traditional sports apparel industry bring some opportunities and challenges. The innovation of science and technology has become an important support for the development of cultural industry. It is an organic integration between the technological innovation and cultural connotation of sportswear products, which can realize the improvement of the value and quality of sportswear products and realize the continuous development of the industry.

\section{The Development Characteristics of the of Start-Ups and Innovation}

Start-ups and innovation that is "mass entrepreneurship and innovation" said Premier Li Keqiang, at the 2014 Summer Davos Forum, and was subsequently promoted in the government work report for 2015. After nearly two years of development, China's double-hit work significantly, to promote China's social structure and the steady development of the economy. Start-ups and innovation is inspiring the entrepreneurial enthusiasm and vitality of ten thousand people in our country. With the promotion of start-ups and innovation, the wave of innovation and entrepreneurship in China shows the following characteristics:

\section{Start-Ups and Innovation Leads the Main Body to the Diversified Development}

Start-ups and innovation achieve the diversification of entrepreneurship development, elite entrepreneurial linkage innovation, grassroots entrepreneurship employment can achieve the diversified development of entrepreneurship. Both enterprises and individuals to achieve 
entrepreneurship can effectively promote economic development. The diversification of entrepreneurial innovation activities, the realization of the upgrading of the industry can achieve an important support for economic growth, and to achieve a positive contribution to the realization of employment.

\section{Start-Ups and Innovation Achieves the Ecological Development of the System}

Start-ups and innovation achieve the coordinated development of large and medium-sized enterprises. Many places have become innovative, entrepreneurial talent habitat, these enterprises and the accumulation of a large number of talent has formed a very complete innovative entrepreneurial ecosystem. The formation of these ecosystems has become an important pillar for the promotion of regional economic growth and the development of high-tech industries.

\section{Start-Ups and Innovation Promotes the High Degree Development of Network}

Online and offline integration is a significant feature of the Internet business, more young, more broad, more active, more fair are the future direction of the Internet business development. The rapid development of Internet technology to achieve a wide range of information sharing, and promote the emergence and development of the new technology, new formats, new models.

\section{The Technology and Culture of Sportswear Products}

Science and technology is the means for the human in the long process of production practice to understand the world and transform the world of knowledge systems and methods. Culture refers to the human in the long-term development of the accumulation of humanistic spirit and material performance of the overall system. Sportswear products as a cultural product, is a scientific and cultural. Sportswear products, the main performance of the current stage of sports apparel manufacturers is in the production of the applied technical capabilities and technological content. Sports and apparel products are more cultural and costume design and the expression of the humanities to express material performance.

There is a contradictory and unified relationship between the technological and cultural nature of sports apparel products, showing some differences and particularity, not only mutually exclusive competition, but also interdependent infiltration. The integration of science and technology and culture through the combination of technological innovation and cultural products can enhance the value and quality of cultural products, so as to further enhance the core competitiveness of products. To achieve sports apparel technology and cultural integration, can effectively improve the quality of sports apparel products, conducive to promoting the rapid development of China's sportswear industry.

\section{The Existing Problems in the Development of Sportswear Industry}

With the continuous improvement of people's health awareness, sports fitness has gradually made people interested in participating in the activities. China's sportswear industry is developing more rapidly, the process of rapid development will inevitably have some problems, to bring some impact to the industry.

First of all, China's sports apparel brand in the design are lack of innovative elements, although there are some brands can do this, but most of the sportswear is still taking the low-end products as the main production products. With the change of people's consumption concept, these low-end products have been difficult to adapt to consumer demand for the product.

Second, the marketing goal is missing. Domestic sports apparel manufacturers in the lack of marketing objectives was caused by that the purpose of production is not clear, the lack of targeted products at this stage of rapid development of the industry competition is difficult to take advantage of. The lack of marketing objectives caused the product can't meet the needs of different consumers, not conducive to industry development.

Finally, the sportswear products of science and technology and culture did not achieve effective integration. Some problems in the design of domestic sportswear, clothing styles and other similar phenomenon, many brands are still in the imitation and plagiarism of the development stage. While 
the high-end sports apparel market needs to be imported. Sportswear products as a product of its scientific and cultural integration is not ideal, and the technical and cultural to show the sports apparel products should be quality.

\section{The Important Significance of Integration of Science and Culture of Sportswear Products under the Trend of Start-Ups and Innovation}

Driven by the start-ups and innovation trend, to achieve sports apparel products, scientific and cultural integration to reach the quality of sports apparel products to enhance the development of China's sports apparel industry has a very positive role. The technological and cultural nature of the product although have some differences in the constituent elements, manifestations and running rules, but both are derived from the practical life of mankind and can play a certain role in promoting the development of single-zone society effect. Sportswear products, scientific and cultural integration is in line with the requirements of the development trend of dual innovation, to achieve product innovation and promote the rapid development of sports apparel industry.

Scientific and cultural integration can stimulate the development of innovative capacity

At present, China's sportswear industry development has some problems, how to achieve the status quo is the problem that the development of sports apparel industry must think about. To achieve the technological and cultural integration of products can effectively stimulate the development of innovative capacity. Innovation ability as an important factor to promote social progress and development is the development of sports apparel industry at this stage of the necessary power support. At the same time, innovation is also the development of China's dual era of great importance and advocacy, including China's industry restructuring direction of mutual unity. Therefore, the realization of sports apparel products, scientific and cultural development can stimulate the development of industry innovation, promote industry progress.

Science and culture integration of sportswear products can show the characteristics and functions

To achieve sports apparel products, scientific and cultural integration can achieve product quality improvement. In the face of China's current production and sales of sports apparel products market, to achieve the improvement of product quality is conducive to China's sports apparel products in the consumer object grade upgrade into the high-end market. Sportswear products as people wear sports clothing, people of their comfort, functionality is a certain requirement, and with the people's health concepts and environmental awareness, user experience has become key factor for people in the choice of products. To achieve the integration of science and technology and culture, the characteristics and functions of sports apparel products have been significantly improved, and thus enhance the user experience, then we help sports apparel products open the market.

The integration of science and technology and culture can provide the core driving force for enhancing the development of sportswear business

Sports apparel products, scientific and cultural and cultural integration significantly enhance the quality and value of the product, and high-quality products will certainly put forward higher requirements for production enterprises. In other words, sports apparel products, scientific and cultural integration of the organic development of the enterprise can strengthen the core, to promote the continuous development of enterprises. Start-ups and innovation is an important direction for the future development of China's industry, the core of enterprise development should also be around this direction. And both scientific and cultural integration of sports apparel enterprises more with the necessary core development of the times, can promote the rapid development of enterprises.

\section{Study on the Strategy of Realizing the Integration of Science and Technology and Cultural of Sportswear Products under the Trend of Start-Ups and Innovation}

Start-ups and innovation era for China's sports apparel industry is to create a favorable development environment. The trend of start-ups and innovation will become an important model for the 
development of all walks of life. To achieve sports apparel products, scientific and cultural integration of the existence is inevitable, and the development of sports apparel industry is of great significance. And actively explore the sports apparel products, scientific and cultural integration of the path and methods to help achieve the trend of dual sports apparel industry, the rapid development of the industry can promote progress.

\section{Update the concept of development, to adapt to the trend of the times}

To achieve sports apparel products, scientific and cultural integration should pay attention to the development of their concept of renewal. China is in the " Mass entrepreneurship and innovation " of the double-generation era, people's value orientation and industry development will tend to this direction, which requires sportswear products in the realization of scientific and cultural integration of the process to focus on the development of the concept of renewal. Under normal circumstances, people for the scientific and cultural views of the existence of a certain one-sided, extreme situation has occurred. Therefore, we should pay attention to sportswear products, scientific and cultural integration of the development concept of renewal. To fully realize that science and technology can contribute to the development of mankind, but it can't bring happiness and dignity to mankind. Therefore, we should pay attention to the development of the concept of renewal, only to achieve the integration of science and technology and culture to be able to achieve sports apparel products in quality and quality improvement, and promote the development of the industry.

Taking people-oriented as the convergence point for the realization of scientific and cultural integration

People-oriented is the core content and soul of our party's ruling idea. People-oriented can best reflect the human in order to achieve complete liberation and freedom of determination and will. Cultural performance can achieve the improvement of people's ideological realm, cultivate sentiment, science and technology can achieve the rationality of people's freedom, the integration of the two embodies the concept of human development, but also achieve the convergence point of scientific and cultural integration. In the process of realizing the science and technology and cultural integration of sportswear products, it is necessary to regard people-oriented as the convergence of the two parties, and meet the growing material and cultural needs of mankind. Will be people-oriented product design and production as the guiding ideology, to achieve a high degree of integration of science and technology and culture to enhance product quality and improve the user experience, and promote the rapid development of sports apparel industry.

\section{Actively promote the sports apparel business system innovation}

The development of the start-ups and innovation trend once again become the main theme of development. To achieve sports apparel products, scientific and cultural integration is the trend of sports apparel industry, and the inevitable choice. Good products on the enterprise requirements more standardized and systematic, so to achieve the sports apparel products, scientific and cultural integration must be on the reform of sports apparel manufacturers, and promote enterprise system innovation. As an important component of China's innovation system, institutional innovation is also in a sense, determines the sports apparel enterprises to enhance the ability to innovate, play an important role in the development of enterprises. We must deepen the reform of science and technology system in the course of the development of sports apparel enterprises, actively build and promote the scientific and technological innovation system, improve the overall efficiency of the enterprise innovation system; continue to deepen the cultural system reform, build an innovative cultural development environment, comprehensive liberation and development.

\section{Conclusion}

To sum up, the start-ups and innovation provides us with an opportunity to realize the repositioning of life values in the context of technological change at this stage. It is an important decision to realize the development of sportswear industry in China under the trend of start-ups and innovation, which is based on the present situation of the development of sportswear industry in China and the realization of the combination of science and technology and culture in the start-ups and innovation trend. To achieve the integration of science and culture of sportswear products for each other can 
effectively achieve product quality improvement, increase the user experience, and promote the sportswear industry, healthy and rapid development. To constantly update the concept of development, adhere to the principle of people-oriented, we can actively promote the garment industry's institutional innovation and reform, in order to achieve the perfect fusion of sportswear products and culture.

\section{References}

[1] Cao Wenhong. The current youth entrepreneurship problem under the "start-ups and innovation" background [J]. Chinese Journal of Youth .2016 (04): 5-9.

[2] Liu Zhanghua. Analysis on the role of government in the start-ups and innovation process [J]. Theory .2016 (12): 66-67.

[3] Liu Yingqiu, Lu Fengyong, Mao Jian. "Mass entrepreneurship and innovation" gave birth to new economic development momentum $[\mathrm{J}]$. Journal of National Institute of Administration .2016 (06).

[4] Liu Junxian. Promote the "start-ups and innovation" what policy dividend [J]. People's Forum .2017 (10).

[5] Lin Cheng. The injury of sports clothing chain brand [J]. China Chain .2015 (05).

[6] Cao Hongmei. Sports clothing market research and analysis [J]. Textile Industry and Technology .2014, 43 (01): 32-33.

[7] Sun Yiliang. China's sports industry brand development strategy research - based on the sporting goods industry independent intellectual property rights innovation empirical analysis [J]. Journal of Wuhan Institute of Physical Education .2010,44 (03): 34-39.

[8] Bi Juan. Beijing culture and technology integration model and path [M]. Beijing: Intellectual Property Press, 2013.

[9] Zhang Haifang. Survey on the status quo of China's sporting goods market and sales [J]. China Business. 2015 (33): 1-3.

[10] Li Mobai. Sportswear brand series reported four: the hope and reef [J]. Chinese clothing. 2016 (06). 